\begin{tabular}{cc}
\hline & International Journal of Engineering \& Technology, $7(4.36)(2018)$ 644-654 \\
SPC & International Journal of Engineering \& Technology \\
\hline
\end{tabular}

\title{
Review Inchemical Structures of Drugs
}

\author{
Nagham Mahmood Aljamali ${ }^{1^{*}}$ \\ ${ }^{I}$ Department of Chemistry, Factuality of Education, Kufa University, Iraq. \\ *Corresponding author_E-mail:dr.nagham_mj@yahoo.com
}

\begin{abstract}
Our review concerned with chemical structures of some drugs in pharmaceutical fields ,some of them used in synthetic field and in synthesis of many drugs and antibiotics.
\end{abstract}

Keywords: structures, common.

\section{Introduction}

Drug discovery is the process of finding new drugs and antibiotics .,some of drugs resulted from natural contents or industrial contents ${ }^{(1-6)}$ like morphine from poppy seeds.

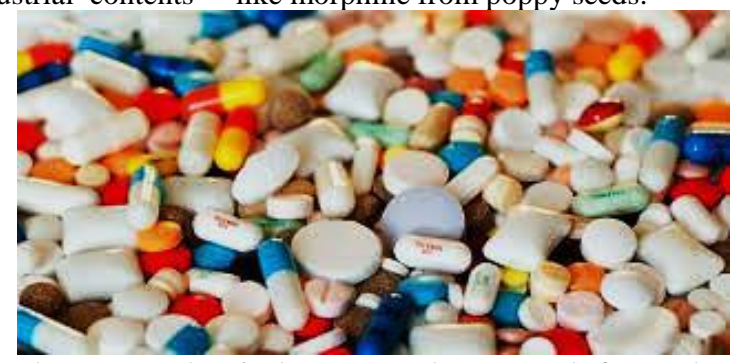

All drugs are chemical compounds, prepared from chemical reactions like condensation reaction, cyclization reaction, elimination reaction, substitution reaction, and all most drugs used in many reaction to formation antibiotics ${ }^{(7-12)}$ and other drugs.

Drugs or Antibiotics are a group of medical compounds that are used to treat infections caused by bacteria ${ }^{(9-18)}$ and fungi.

Index ${ }^{(4,6)}$ of Common drugs , Antibiotics for interesting, collected from references:

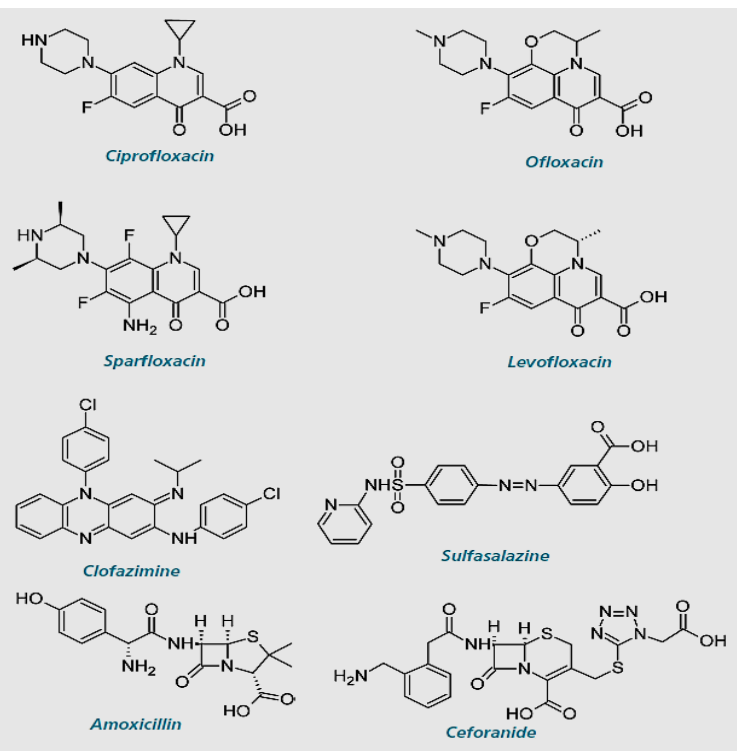

Some of drugs involved functional groups in their structures which used in synthesis of other drugs and antibiotics like: 

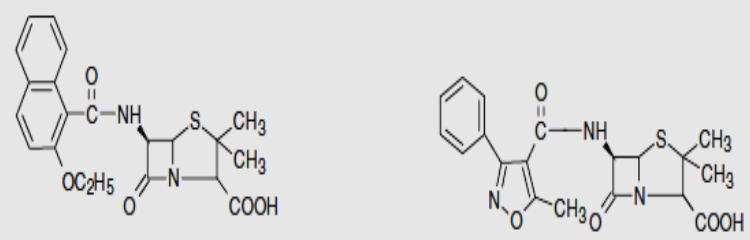

Nafcillin
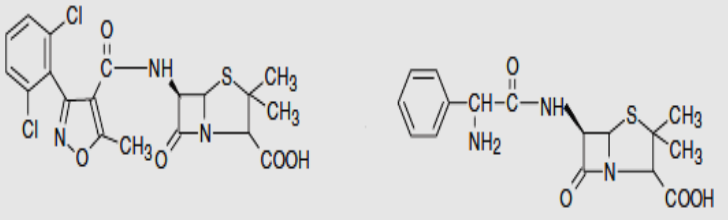

Dicloxacillin
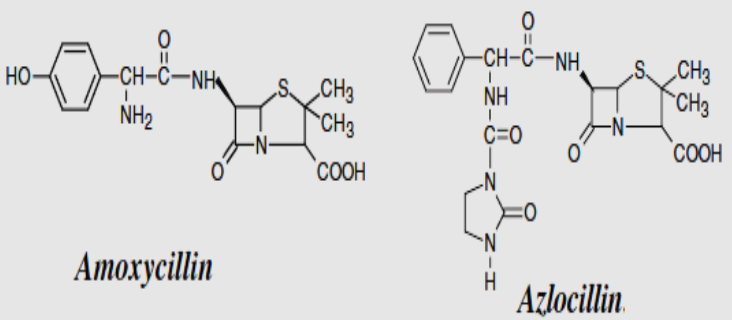

Amoxycillin

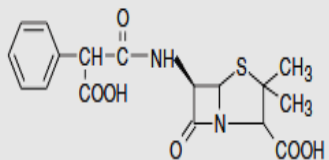

Carbenicillin

\section{Oxacillin}

\section{Ticarcillin}

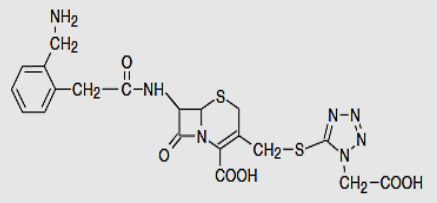

Ceforanide

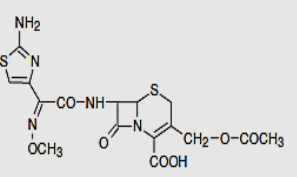

Cefotaxime

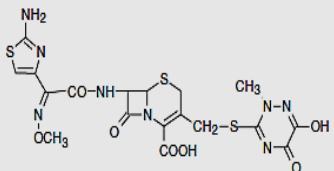

Ceftriaxone

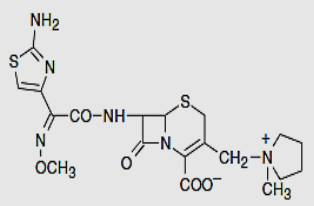

Cefepime
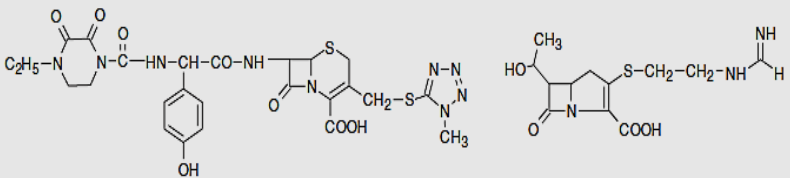

Cefoperazone

Imipenem

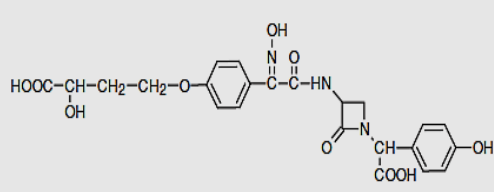

nocardicin A

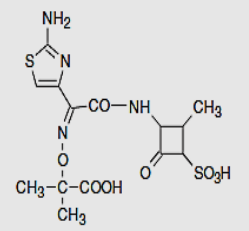

Aztreonam. 


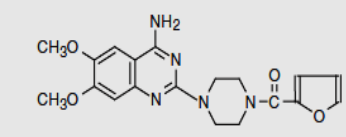

Prazosin

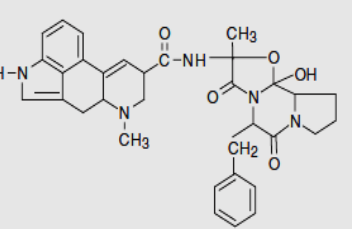

Ergotamine

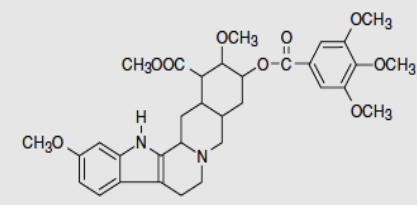

Reserpine

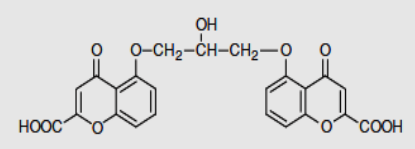

Cromolyn

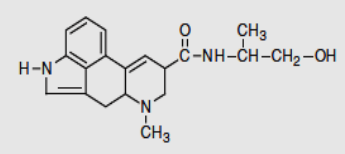

Ergonovine

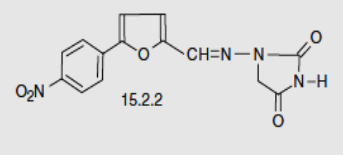

Dantrolene

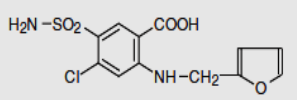

Furosemide.

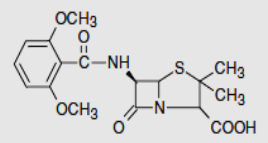

Methicillin

隹

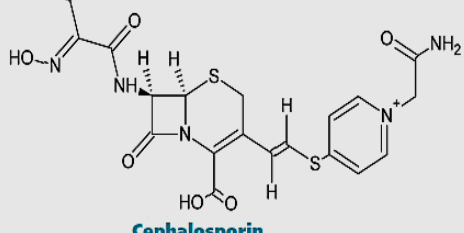

Sulfazecin

$\int_{\mathrm{HCl}}^{\mathrm{N}}$

Clindamycin

Platensimycin
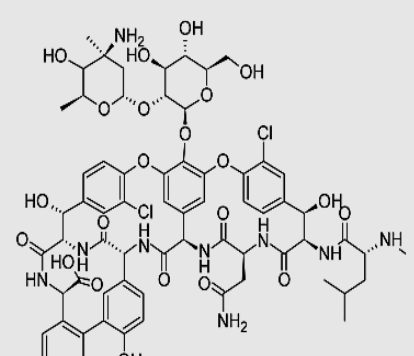

$\mathrm{H}$<smiles>CC1(c2ccccc2)C(=O)NC(=O)NC1=O</smiles>

Phenobarbital

0

$\mathrm{CH}_{3} \mathrm{HN} \cdot \mathrm{C}-\mathrm{NHCH}_{2} \mathrm{CH}_{2}-\mathrm{S}-\mathrm{CH}_{2}$<smiles>Cc1c[nH]cn1</smiles>

Cimentidine
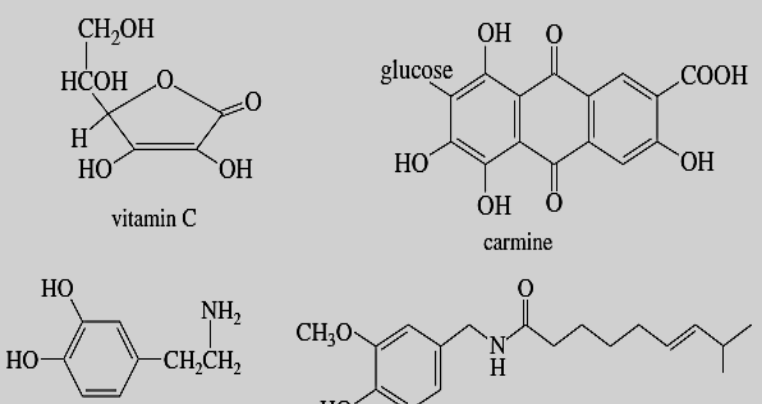

dopamine<smiles>COc1cc(CNC(=O)CCCCC=CC(C)C)ccc1O</smiles>

capsaicin
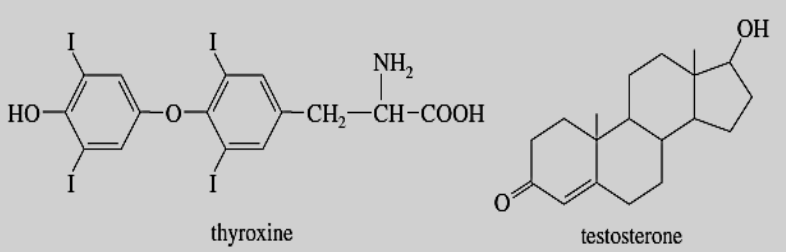

\section{Penicillin G}



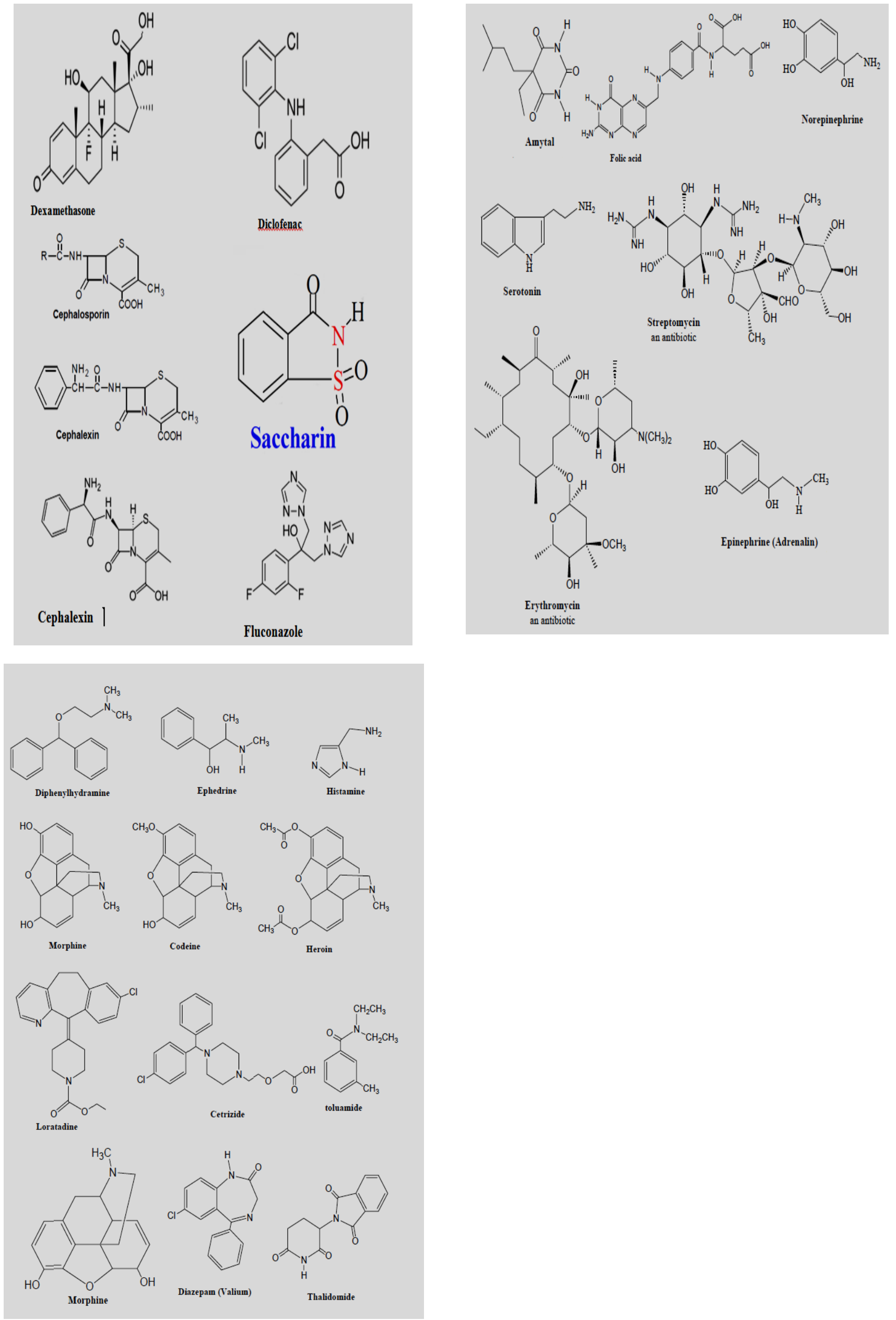

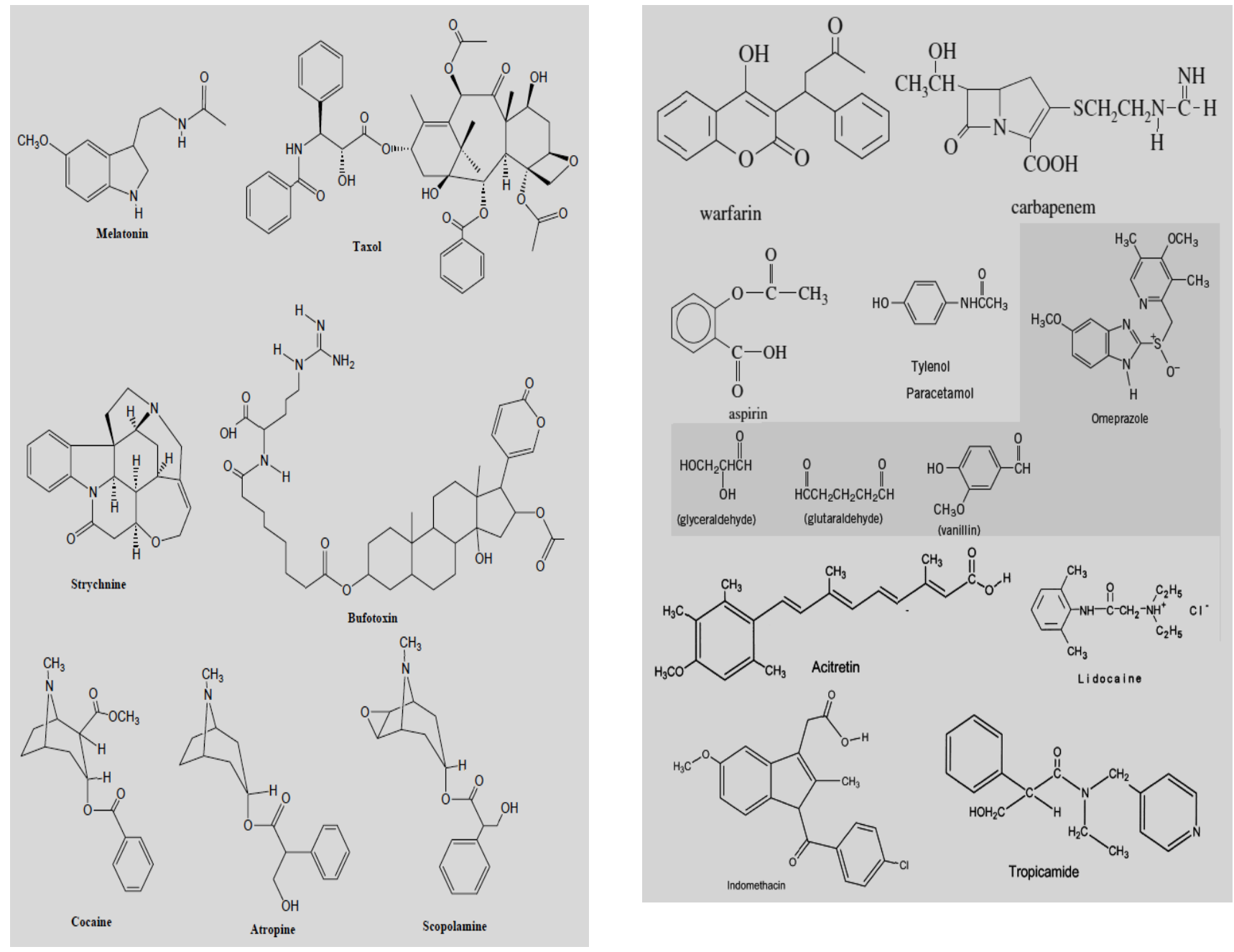


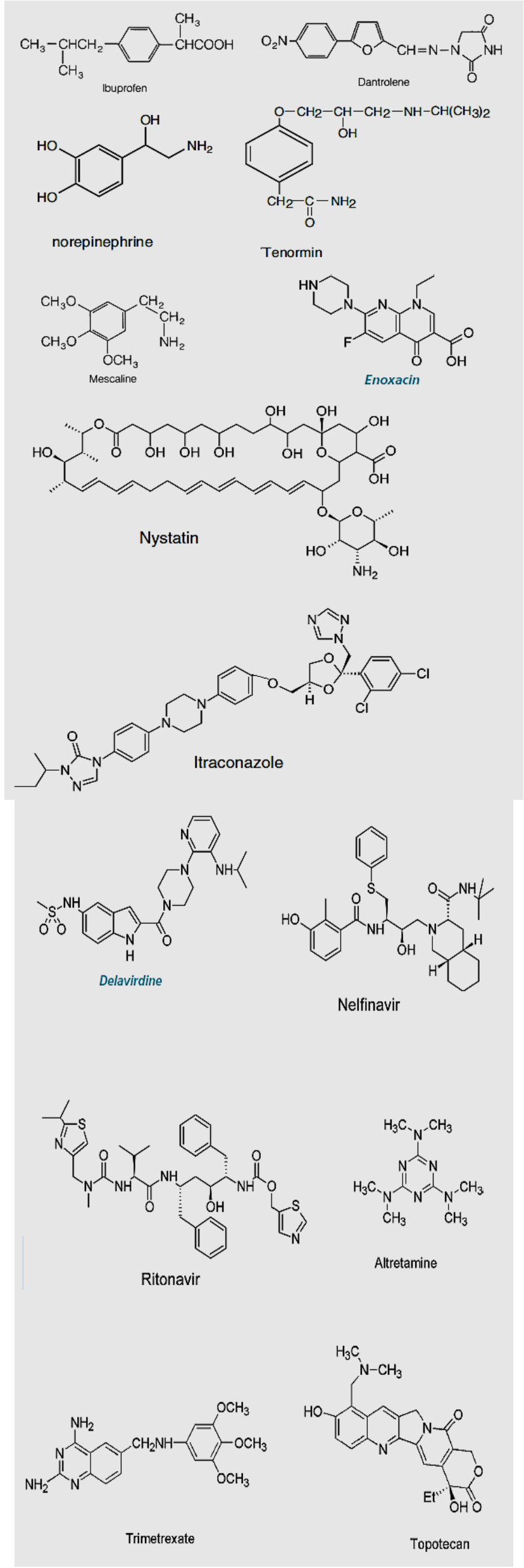

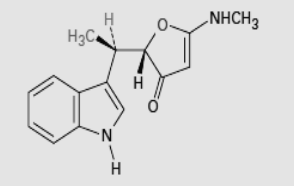

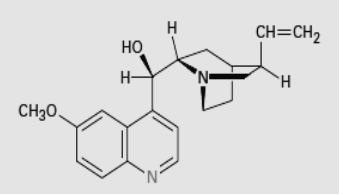

Indolmycin
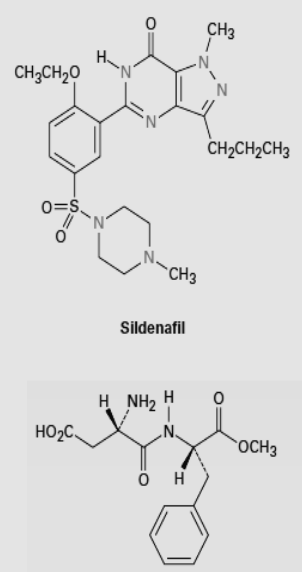

Aspartame
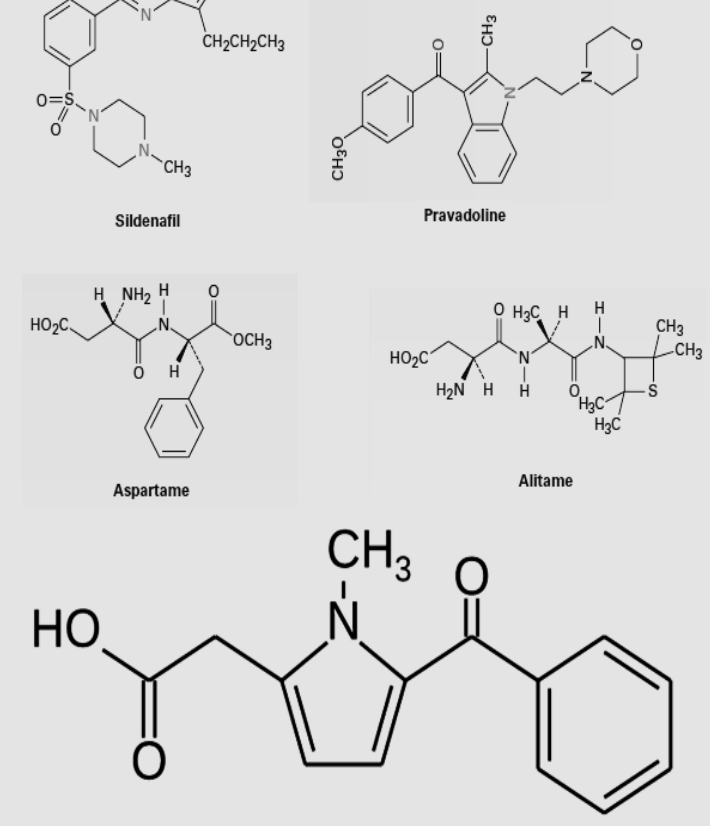

Tolmetin 


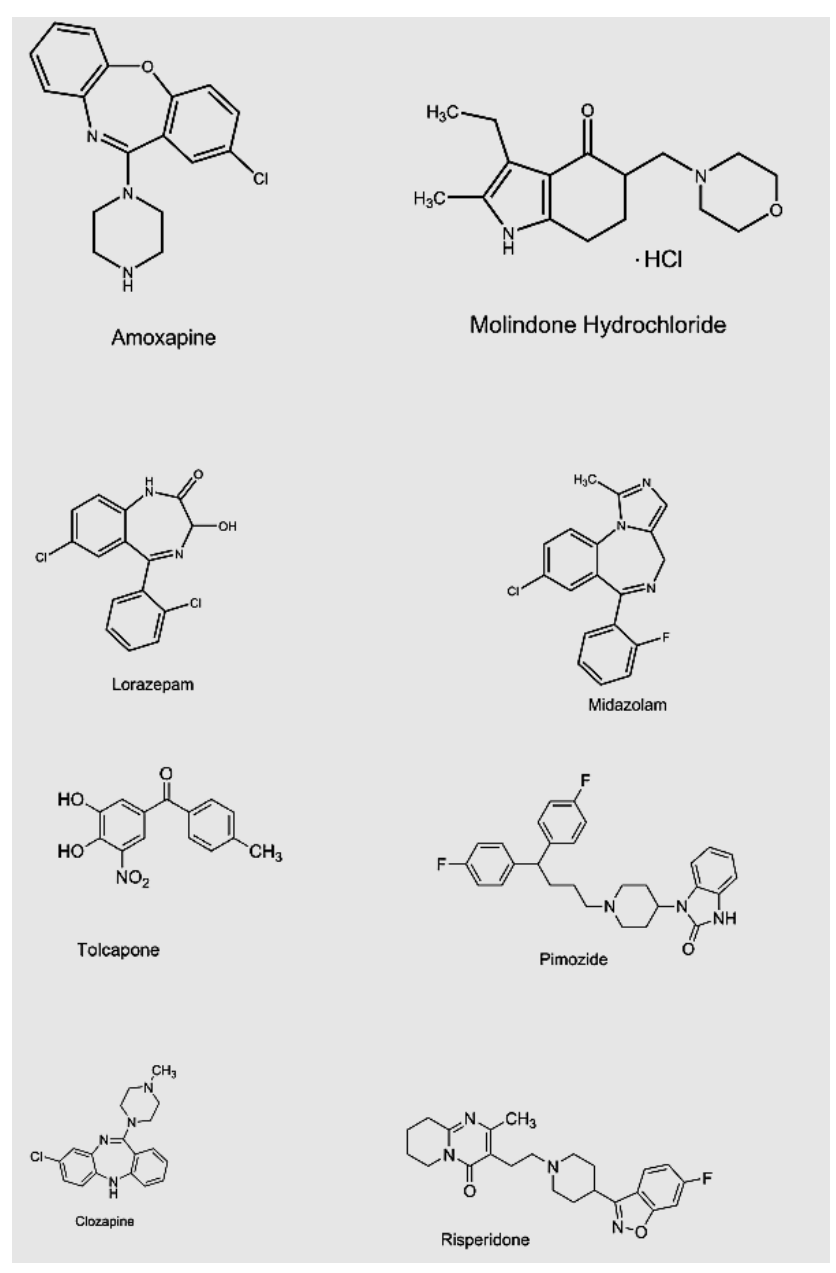

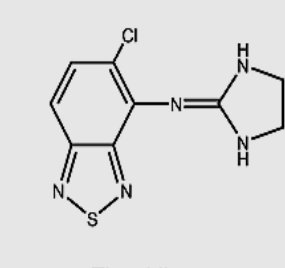

Tizanidine

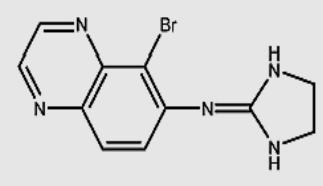

Brimonidine

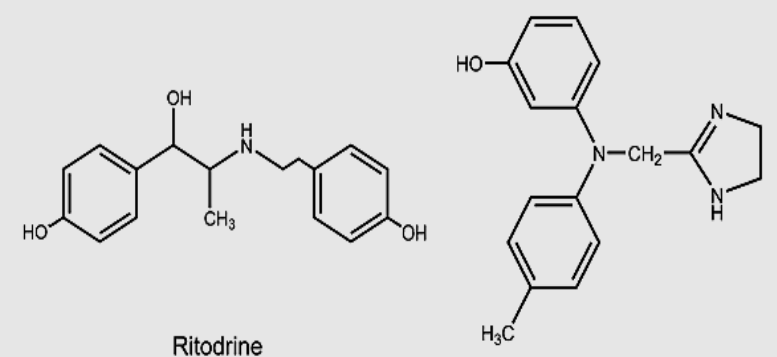

Phentolamine

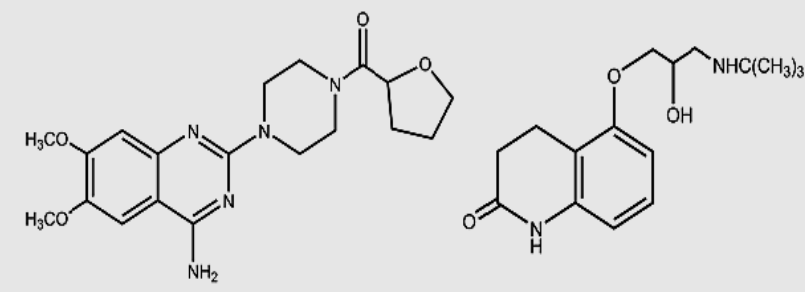

Terazosin

Carteolol

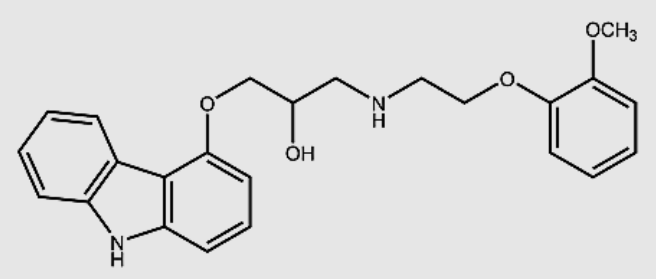

Carvedilol

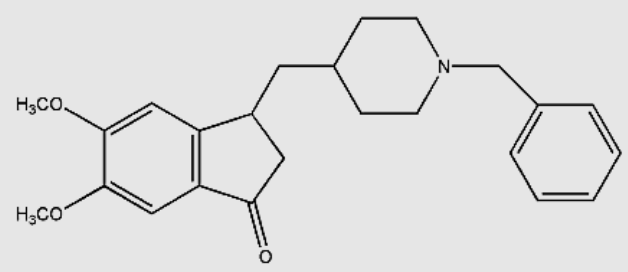

Donepezil
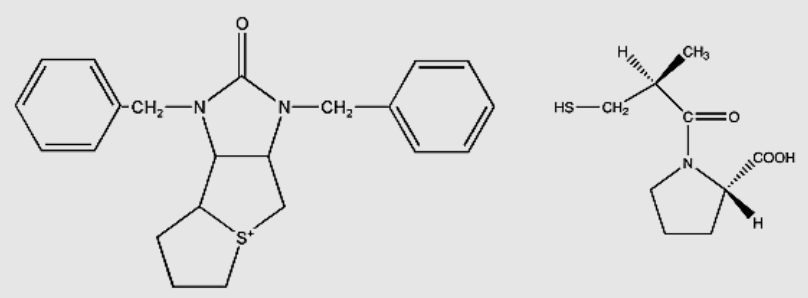

Trimethaphan Camsylate 


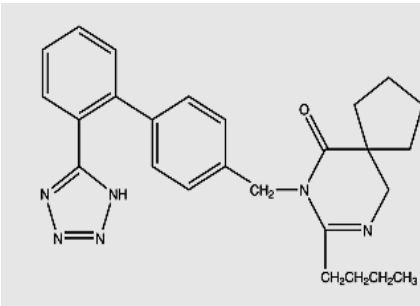

Irbesartan

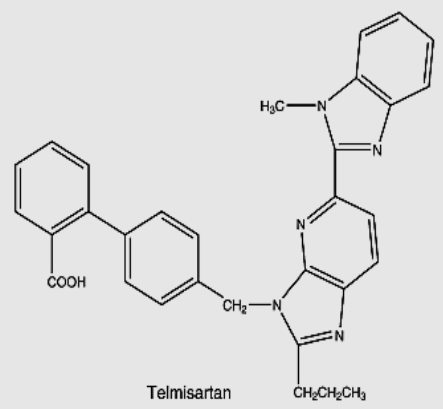

Telmisartan

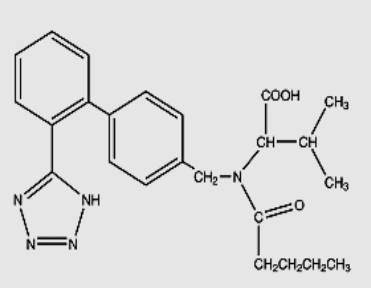

Diovan

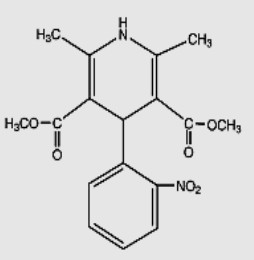

Nifedipine

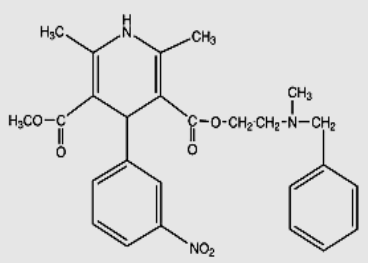

Cardene

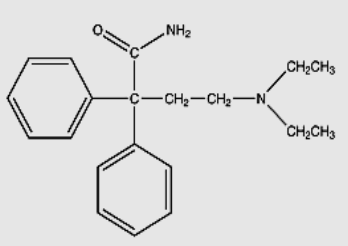

Norpace

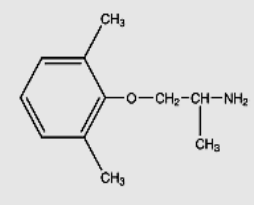

Mexiletine

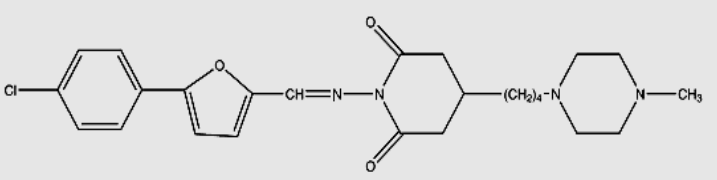

Azimilicto

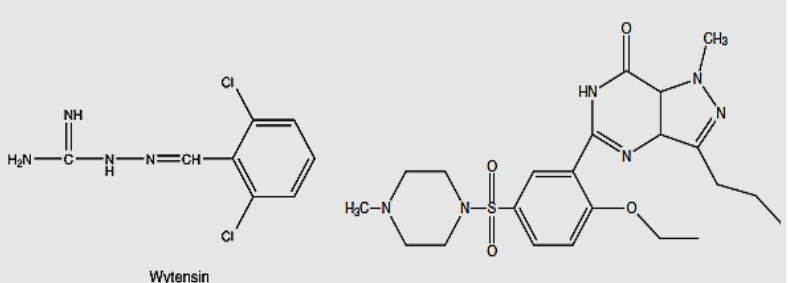

Wytensin

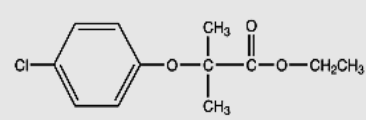

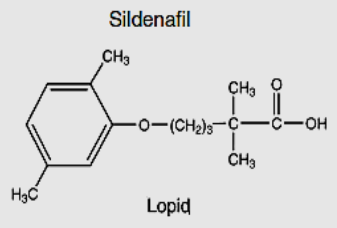

Ranolazine

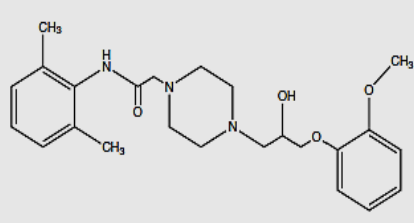

Ranolazine 

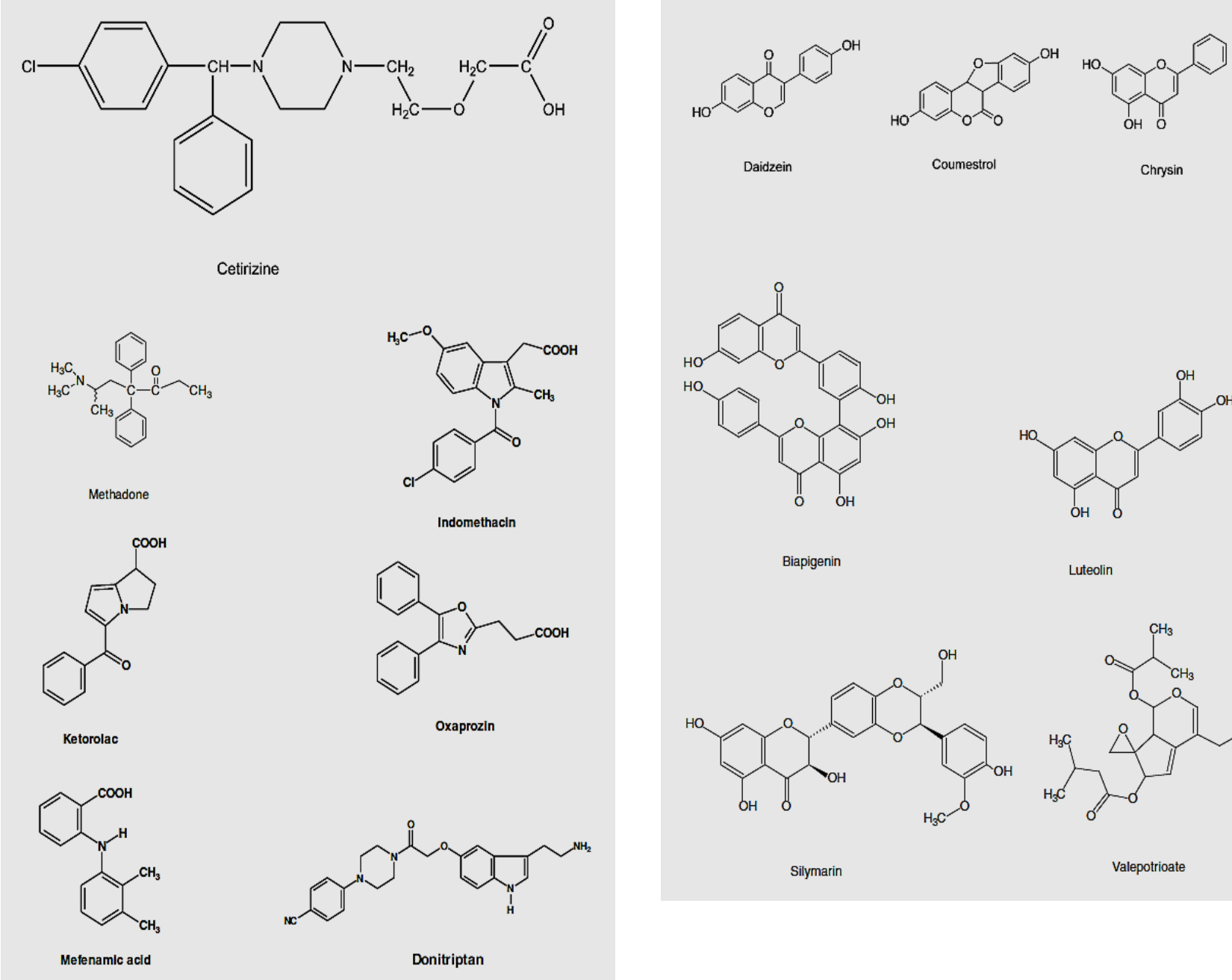

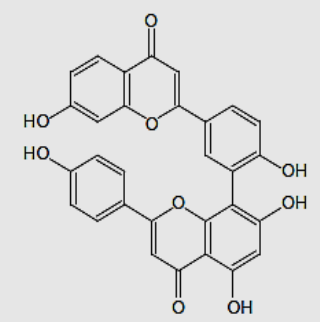

Biapigenin

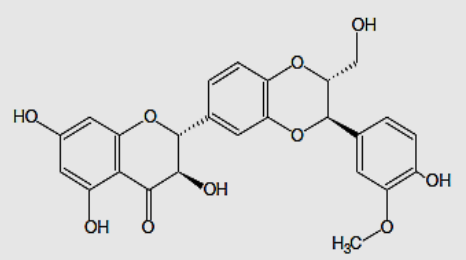

Silymarin

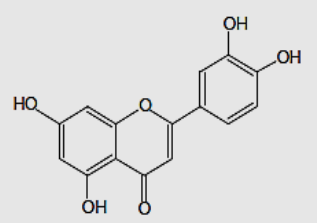

Luteolin

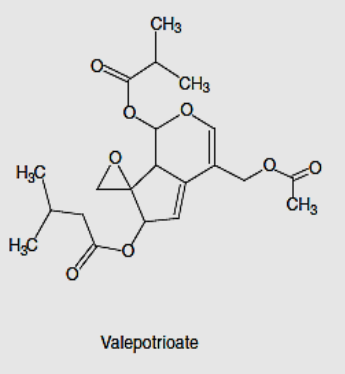




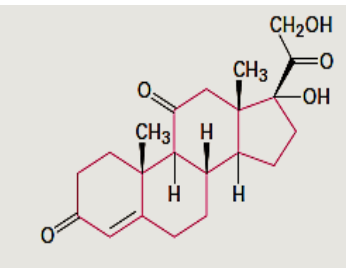

Cortisone<smiles>O=C(Cl)N[C@@H](CO)[C@H](O)c1ccc([N+](=O)[O-])cc1</smiles>

Chloramphenicol

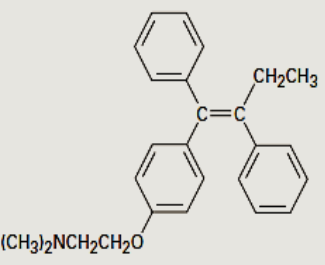

Tamoxifen

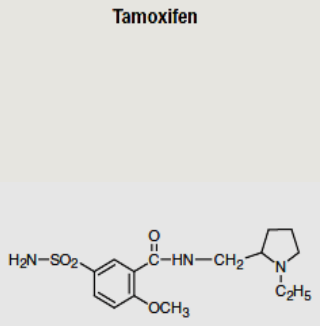

Sulpiride

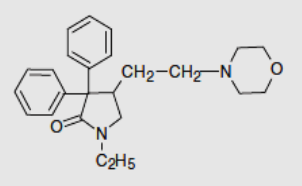

Doxapram

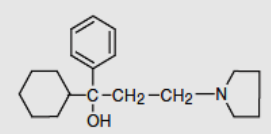

Procyclidine

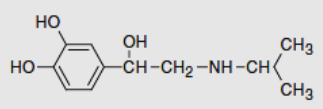

- $-{ }_{\mathrm{C}}^{\mathrm{CH}}-\mathrm{NH}_{3}-\mathrm{CH}_{2}-\mathrm{CH}_{2}-\mathrm{OH}$

Isoproterenol<smiles>C=C(C)C1CC=C(C)C(=O)C1</smiles>

Carvone

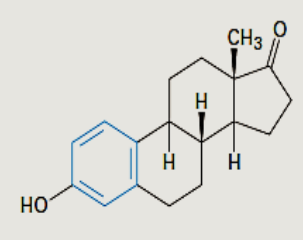

Estrone

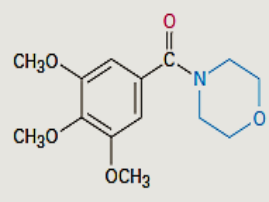

Trimetozine

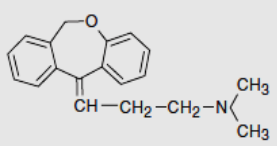

Doxepin.

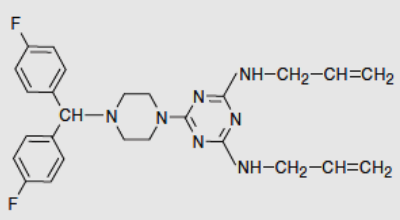

Almitrine

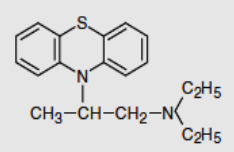

Ethopropazine

Ritodrine

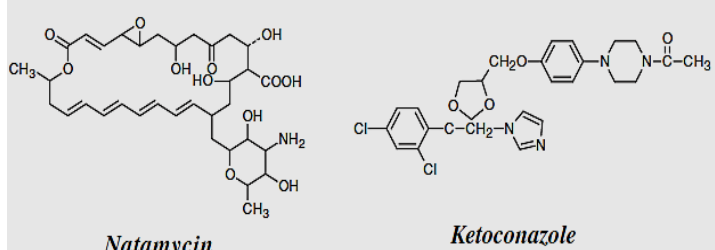

Natamycin

Ketoconazole<smiles>Clc1ccc(COCc2ccc(Cl)cc2Cn2ccnc2)c(Cl)c1</smiles>

Econazole<smiles>CC1CN(c2c(F)c(N)c3c(=O)c(C(=O)O)cn(C4CC4)c3c2F)CC(C)N1</smiles>

Sparfloxacin<smiles>CN(Cc1cnc2nc(N)nc(N)c2n1)c1ccc(C(=O)NC(CCC(=O)O)C(=O)O)cc1</smiles>

Methotrexate<smiles>CC1NCc2ccc(-c3ccc4c(=O)c(C(=O)O)cn(C5CC5)c4c3OC(F)F)cc21</smiles>

Garenoxacin

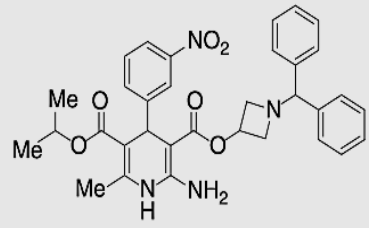

Azelnidipine

\section{Conclusion}

All drugs are chemical compounds, prepared from chemical reactions like condensation reaction, cyclization reaction, elimination reaction, substitution reaction, and all most drugs used in many reaction to formation antibiotics and other drugs.

\section{References}

[1] Kubinyi H, "Chance favors the prepared mind--from serendipity to rational drug design", J. Recept. Signal Transduct. Res., Vol.19, No.1-4, (1999), pp.15-39.

[2] Mayr LM \&Bojanic D, "Novel trends in high-throughput screening", Current Opinion in Pharmacology, Vol.9, No.5, (2009), pp.580-588.

[3] Ertl P, "Cheminformatics analysis of organic substituents: identification of the most common substituents, calculation of substituent properties, and automatic identification of drug-like bioisosteric groups", Journal of chemical information and computer sciences, Vol.43, No.2, (2003), pp.374-380.

[4] Bohacek RS, McMartin C \&Guida WC, "The art and practice of structure-based drug design: a molecular modeling perspective", Medicinal research reviews, Vol.16, No.1, (1996), pp.3-50.

[5] Leiter DP, Morgan HL \&Stobaugh RE, "Installation and Operation of a Registry for Chemical Compounds", Journal of Chemical Documentation, Vol.5, No.4, (1965), pp.238-242.

[6] LednicerD, The organic chemistry of drug synthesis, John Wiley \& Sons, (2007).

[7] NaghamMAljamali, Experimental Methods for Preparation of Mannich Bases, Formazan, Normal and Cyclic Sulfur Compounds, 1 Edt., Evince pub Publishing house, (2018). 
[8] NaghamMAljamali, Reactions and Mechanisms, 1 Edt., IJMRA Publication, (2018).

[9] Fink T \&Reymond JL, "Virtual exploration of the chemical universe up to 11 atoms of C, N, O, F: assembly of 26.4 million structures (110.9 million stereoisomers) and analysis for new ring systems, stereochemistry, physicochemical properties, compound classes, and drug discovery", Journal of chemical information and modeling, Vol.47, No.2, (2007), pp.342-353.

[10] Wright GD, "The antibiotic resistome: the nexus of chemical and genetic diversity", Nature Reviews Microbiology, Vol.5, No.3, (2007), pp175-186.

[11] Nagham MAljamali, "Synthesis and chemical identification of macro compounds of (Thiazol and Imidazol)", Research J. Pharm. and Tech, Vol.8, No.1, (2015), pp.78-84.

[12] Hegazi A, Abdou AM, El-Moez S \& Allah FA, "Evaluation of the antibacterial activity of bee venom from different sources", World Applied Sciences Journal, Vol.30, No.3, (2014), pp.266-270.

[13] Intisar OA, Nuha SS, ZainabMJ \&Nagham MAljamali, "Synthesis of New Organic Compounds Via Three Components Reaction with Studying of (Identification,Thermal Behavior, Bioactivity on Bacteria of Teeth)", Journal of Global Pharma Technology, Vol.11, No.9, (2017), pp.157-164.

[14] Eman HS\&Nagham MAljamali, "New Azo-Thiadiazole Ligands (Preparation, Spectral, Thermal, Biochemical, Physical properties)Studying", Journal of Global Pharma Technology, Vol.11, No.9, (2017), pp.165-173.

[15] Nagham MAljamali, "Preparation, Spectral Investigation, Thermal Analysis, Biochemical Studying of New (Oxadiazole-Five Membered Ring)-Ligands", Journal of Global Pharma Technology, Vol.10, No.1, (2018), pp.20-29.

[16] Intisar Obaid A, Eman HS \&Nagham MAljamali, "Synthesis of (Tetrazole, Oxazepine, Azo, Imine) Ligands and Studying of Their (Organic Identification, Chromatography, Solubility, Physical, Thermal Analysis, Bio-Study)", Research J. Pharm. and Tech., Vol.11, No.7, (2018).

[17] Mohammed M, Nagham MAljamali, Shubber WA \&Abdalrahman SA, "New Azomethine-Azo heterocyclic ligands via cyclization of ester", Research Journal of Pharmacy and Technology, Vol.11, No.6, (2018), pp.2555-2560.

[18] Benecke C, Grund R, Hohberger R, Kerber A, Laue R \& Wieland $\mathrm{T}$, "MOLGEN+, a generator of connectivity isomers and stereoisomers for molecular structure elucidation", AnalyticaChimicaActa, Vol.314, No.3, (1995), pp.141-147. 